\title{
Modeling and Simulation on Complex System Life Cycle Risk Dynamic Evolution
}

\author{
Yifan $\mathrm{Xu}^{*}$, Jianwei Lv, Peng Di and Zongren Xie \\ Dept. of Management Engineering \\ Naval Univ. of Engineering \\ Wuhan, China \\ * Corresponding author
}

\begin{abstract}
Complex system life cycle management is system engineering involving high technology, high investment and high risk. This paper studied risk evolution and risk level distributions on different stages during complex system life cycle. Taking into account risk propagation and feedback influence, the risk evolution of complex system life cycle was modeled based on system dynamics. The risk levels distributed on all stages of system life cycle were simulated by system dynamic model. The simulation results are helpful to understand that the initial stages of life cycle are more flexible and valuable to change for risk management. Additionally, sensitivity analysis illuminates that different system types of risk have different risk distributions among stages of life cycle and hereby different emphasis of risk management during life cycle should be considered according to different system types of risk.
\end{abstract}

Keywords-complex system; system life cycle; risk evolution; system dynamics; modeling and simulation

\section{INTRODUCTION}

Complex system life cycle management is system engineering involving high technology, high investment and high risk. Ordinarily, complex system life cycle can be divided into six main stages, i.e., argumentation, design, construction, testing, operation, retirement. During each stage of life cycle, there will be management objectives and plans. However, it is unavoidable that all kinds of uncertainties influence accomplishment of system objectives and plans. These uncertainties and their influence constitute risk during life cycle of complex systems. For risk analysis and management of complex system life cycle, single-stage and static research has be well discussed in literature, comparing with multiplestage and dynamic research. In this paper, the life cycle risk dynamic evolution and risk level distributions will be under research.

Risk evolution may have other expressions, such as risk propagation, risk chain, risk evolvement, risk relevance, etc. Nowadays, risk dynamic researches on risk evolution become a main trend. The related researches are summarized as follow. $\mathrm{K}$. Cooper [1] used system dynamics models to analyze cost overrun in naval ship building, which helped ship manufacturer Ingalls retrieved loss for U.S Navy changing warship design. Laverghetta [2] adopted system dynamics to analyze risk about cost, plan and efficiency in complex ship design. NASA Jet Propulsion Laboratory [3] took into account influence of operational risk feeding back to research stage. Cunbin Li [4] put forward risk element transmission theory based on risk elements. Yuanming Wang [5] studied risk transmission and its control for project supply chain. Dayong Li [6] studied evolvement and modeling of risk in naval ship engineering.

This paper studies risk evolution and risk level distributions on different stages during complex system life cycle based on system dynamics simulation. Section 2 discusses the motivation and methodology of risk dynamic evolution modeling and simulation. Section 3 presents causal relationships during system life cycle, and builds risk evolution model by system dynamics. Section 4 designs variables and parameters configuration, and executes simulations and sensitivity analysis according to different system types of risk. Finally, Section 5 concludes this paper and discusses further research.

\section{METHODOLOGY}

The development of complex system usually contains concurrent, iterative and coupling processes. The complex system development has not been completely "standardized". This kind of evolution can be depicted as a spiral process $[7,8]$. The spiral process repeats regular steps, including concept development, system level design, detailed design, and integration and testing. In practice, as regard to complex system, spiral process requires more prospective understanding for design. Design not only focuses on system realization, but also need early consideration on operation, maintenance and support in the view of system life cycle. Designing for sustainability requires the consideration of cycle performance and life cycle cost throughout the complex system life.

The applications of Integrated Product and Process Development (IPPD), concurrent engineering, and Integrated Design Environments (IDE) have successfully dealt with complex productions or systems. Based above technologies, multi-disciplinary teams, representing all potential elements of design, production, and life cycle support, can examine all aspects of the design (requirements, technology alternatives, cost, manning, especially integrated logistic support, etc.) as early as possible in the design process[7]. The methodology builds on the premise that the greatest leverage for life cycle 
management is only achievable in initial development, when the design is most flexible to change.

Complex system life cycle forms a network process in which tasks relating to risk management are considered early in the design. Therefore, critical to understanding the implementation of such process improvements is the recognition of the multiple, objective influences any one methodology will cause[7]. System dynamic model can provides a basic structure about system development[9]. The model can assess process improvements that incorporate both system changes to the processes and the influences of nonlinear responses such as influence networks of risk management. The risk evolution model can be built to describe these processes and influences based on system dynamics.

\section{System Dynamics Modeling}

Throughout complex system life cycle, associated influence and risk evolution related to risk management are depicted by system dynamic model. The risk propagation and feedback influence relationships shape a network structure.

\section{A. Risk Evolution Relationship}

In Figure 1, the risk evolution relationships among stages of complex system life cycle is modeled by stage nodes, i.e. "Argumentation", "Design", "Construction", "Testing", "Operation" and "Retirement". Blue arrows indicate risk propagation, while red arrows represent risk feedback influence that can be helpful to improve risk mitigation for the same or similar systems. In system dynamic, Figure 1 actually depicts the casual relationship diagram.

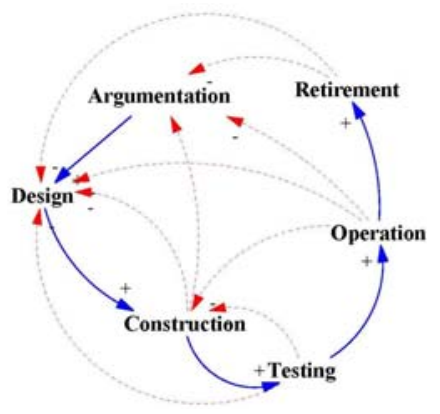

FIGURE I. RISK EVOLUTION RELATIONSHIPS AMONG STAGES OF COMPLEX SYSTEM LIFE CYCLE

\section{B. System Dynamics Model}

The life cycle of complex system is comprised with "Argumentation", "Design", "Construction", "Testing", "Operation" and "Retirement". Risk managing tasks related to all stages will effect and influence many aspects particularly after delivery. The effect and influence are regarded as propagating risk. Suppose that managing risk is definitive at each stage during a certain system life cycle. In Figure 2, risk intensity is distinguished by marking the first letter of stage respectively. And others are named by the same way.

At each stage, related risk management tasks are under consideration and disposal which will partially mitigate risk at corresponding stage. The remaining risk, not having been recognized or mitigated, will be propagated to the latter stages. With regard to complex system, the experience obtained from system life cycle is continuous, comparable and referrible. Besides risk propagation, risk mitigation at latter stage may provide feedbacks (red arrows in Figure 2) for improvement of the same or similar systems. The feedback influence is helpful to risk mitigation undoubtedly. It is needed to be explained that the level variables "Argumentation", "Design", "Construction", "Testing", "Operation" and "Retirement" on the right side of Figure 2 are duplicate "ghost" variables for building graphic model conveniently. In Table 1 (at the end of paper), model variables and their relation equations are designed in detail.

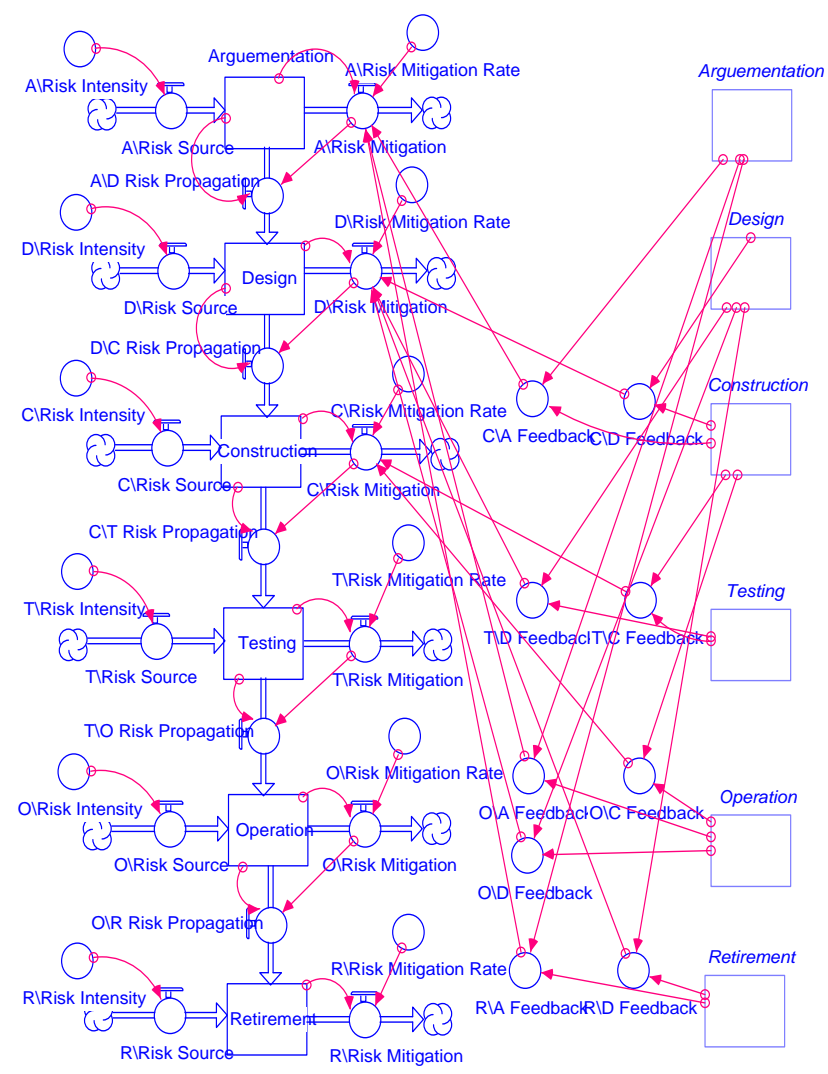

FIGURE II. SYSTEM DYNAMICS MODEL OF COMPLEX SYSTEM RISK EVOLUTION

\section{Simulations}

Based on system dynamic model proposed in Section III, the variables and parameters are detailed at first. And then, simulations are execute by system dynamic software iThink ${ }^{\circledR}$ Stella 10.0. Moreover the sensitivity analysis is given for comparing different system types of risk.

\section{A. Configuration of Variables and Parameters}

In Table 2, configuration of variables and parameters sets all "constant" variable values for system dynamic model. For the further sensitivity analysis among different system type, different groups of configurations are listed in Table 2 . 
These risk levels are ranked by risk intensity from 0-6, respectively according to "very low", "low", "relatively low", "medium", "relatively high", "high", and "very high".

Risk mitigation capability is depicted as a numerical metric between 0 and 1 . From low risk mitigation capability to high, 7 ranks of this metric are arranged from 0 to 1 , respectively according to "very low", "low", "relatively low", "medium", "relatively high", "high", and "very high".

TABLE II. CONFIGURATION OF VARIABLES AND PARAMETERS

\begin{tabular}{|c|c|c|c|c|c|}
\hline Type & Name & Property & I & II & II \\
\hline \multirow{4}{*}{$\begin{array}{c}\text { Risk } \\
\text { Intensity } \\
\text { of Stage }\end{array}$} & $\mathrm{A} \backslash$ Risk Intensity & Constant & 5.0 & 6.0 & 3.0 \\
\cline { 2 - 6 } & $\mathrm{D} \backslash$ Risk Intensity & Constant & 6.0 & 6.0 & 4.0 \\
\cline { 2 - 6 } & $\mathrm{C} \backslash$ Risk Intensity & Constant & 6.0 & 6.0 & 4.0 \\
\cline { 2 - 6 } & $\mathrm{T} \backslash$ Risk Intensity & Constant & 4.0 & 5.0 & 3.0 \\
\cline { 2 - 6 } & $\mathrm{O} \backslash$ Risk Intensity & Constant & 2.0 & 4.0 & 2.0 \\
\hline \multirow{4}{*}{$\begin{array}{c}\text { Risk } \\
\text { Ratigation of } \\
\text { Stage }\end{array}$} & $\mathrm{R} \backslash$ Risk Intensity & Constant & 1.0 & 3.0 & 1.0 \\
\cline { 2 - 6 } & $\mathrm{A} \backslash$ Risk Mitigation Rate & Constant & 0.4 & 0.5 & 0.5 \\
\cline { 2 - 6 } & $\mathrm{D} \backslash$ Risk Mitigation Rate & Constant & 0.5 & 0.6 & 0.5 \\
\cline { 2 - 6 } & $\mathrm{C} \backslash$ Risk Mitigation Rate & Constant & 0.5 & 0.6 & 0.5 \\
\cline { 2 - 6 } & $\mathrm{T} \backslash$ Risk Mitigation Rate & Constant & 0.6 & 0.6 & 0.6 \\
\cline { 2 - 6 } & $\mathrm{O} \backslash$ Risk Mitigation Rate & Constant & 0.7 & 0.8 & 0.7 \\
\cline { 2 - 6 } & $\mathrm{R} \backslash$ Risk Mitigation Rate & Constant & 0.8 & 0.8 & 0.8 \\
\hline
\end{tabular}

TABLE III. SETTINGS OF RISK METRICS

\begin{tabular}{|c|c|c|c|}
\hline \multicolumn{2}{|c|}{ Risk Level (RL) } & \multicolumn{2}{c|}{ Risk Mitigation (RM) } \\
\hline $\mathrm{RL} \geq 6$ & Very High & $0.8<\mathrm{RM} \leq 1$ & Very High \\
\hline $5 \leq \mathrm{RL}<6$ & High & $0.7<\mathrm{RM} \leq 0.8$ & High \\
\hline $4 \leq \mathrm{RL}<5$ & Relatively High & $0.6<\mathrm{RM} \leq 0.7$ & Relatively High \\
\hline $3 \leq \mathrm{RL}<4$ & Medium & $0.5<\mathrm{RM} \leq 0.6$ & Medium \\
\hline $2 \leq \mathrm{RL}<3$ & Relatively Low & $0.4<\mathrm{RM} \leq 0.5$ & Relatively Low \\
\hline $1 \leq \mathrm{RL}<2$ & Low & $0.3<\mathrm{RM} \leq 0.4$ & Low \\
\hline $0 \leq \mathrm{RL}<1$ & Very Low & $0<\mathrm{RM} \leq 0.3$ & Very Low \\
\hline
\end{tabular}

\section{B. Simulation Results}

Arrange risk intensity and risk mitigation rate at each stage shown in Tab.1. Risk intensity and risk mitigation represents risk level and capability of risk mitigation. The model shown in Figure 2 is simulated by system dynamic software iThink ${ }^{\circledR}$ Stella 10.0.

Considering feedback, risk levels are shown in Figure 3(a). Contrarily, risk levels without feedback are shown in Figure 3(b). Average risk levels are listed for different system types in Table 4. The difference between "Average Risk 0" and "Average Risk I" depends on whether feedback is under consideration. It is shown that feedback is helpful to mitigate risk and risk feedback influence should be undertaken and exploited at early stages. Besides, simulation parameters listed in Table 2 also reveal system type and risk mitigation capability according to "Average Risk II" and "Average Risk III".

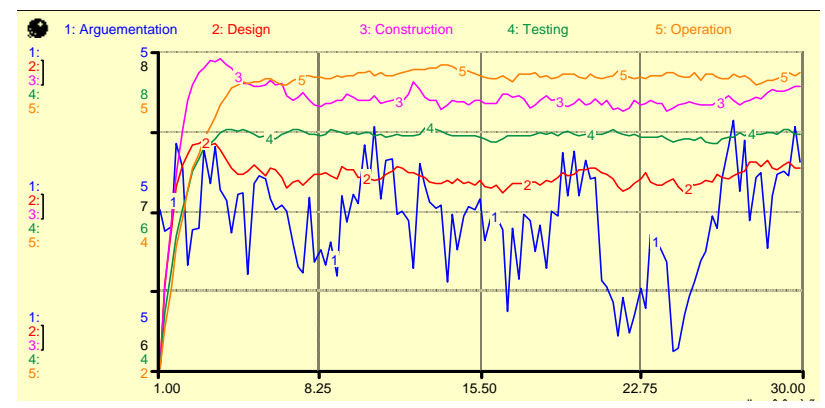

(a)

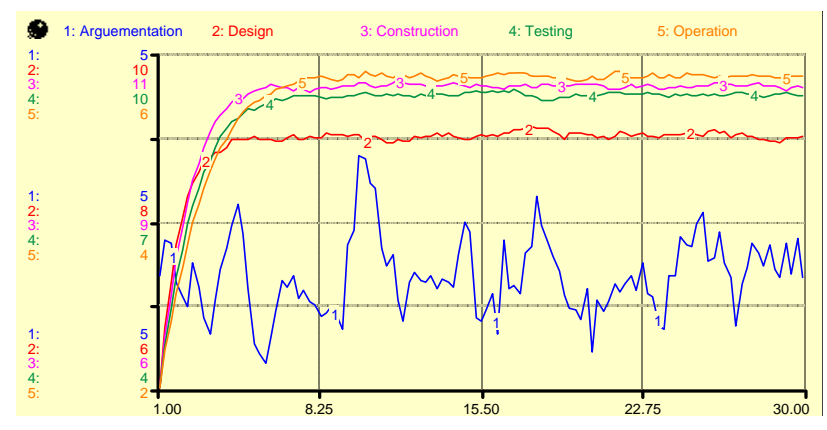

(b)

FIGURE III. RISK LEVELS AT STAGES OF COMPLEX SYSTEM LIFE CYCLE

TABLE IV. SIMULATION RESULtS

\begin{tabular}{|c|c|c|c|c|c|c|}
\hline $\begin{array}{c}\text { Stage } \\
\text { Abbreviation }\end{array}$ & A & D & C & T & O & D \\
\hline Average Risk 0 & 4.99 & 8.94 & 10.38 & 9.07 & 5.54 & 2.89 \\
\hline Average Risk I & 5.00 & 7.22 & 7.70 & 6.89 & 4.71 & 2.65 \\
\hline Average Risk II & 5.99 & 7.14 & 6.74 & 6.43 & 6.52 & 4.74 \\
\hline Average Risk III & 3.01 & 4.16 & 4.61 & 4.53 & 3.79 & 2.33 \\
\hline
\end{tabular}

Table 4 shows the comparison among different system types by sensitivity analysis. The indicating label " 0 " to "III" represents "No feedback influence", "Common risk", "High risk" and "Low risk" respectively. Obviously, risk levels of stages will be reduced remarkably by considering the improvement by feedback influence. Furthermore, the risk distributions among stages of system life cycle exhibit differently from type I to type III. For "Common risk" type, high risk level mainly assembled in design and construction stage. For "High risk" type, the higher risk stages are likely to move forward at early stages, such as argumentation and design, comparing with "Common risk" type.

\section{CONCLUSIONS}

Risk analysis and management tasks are challenging and prospective for complex system life cycle. The traditional sequential working mode cannot guarantee the efficient work for complex system development. The idea of risk dynamic evolution provides a different thinking and view. Based on system dynamic model depicting risk evolution, it is suitable and convenient to understand and analyze risk propagation at 
different influential levels and life cycle stages. The model and simulations catch hold of global laws and feedback processes. The simulation results are helpful to understand that the initial stages of life cycle are more flexible and valuable to change for risk management. Additionally, sensitivity analysis illuminates that different system types of risk have different risk distributions among stages of life cycle and hereby different emphasis of risk management during life cycle should be considered according to different system types of risk.

In this paper, the risk evolution model, based on System Dynamics, is capable of dynamic analysis. However, the details of stages in the proposed model are not abundant. Complex systems may contain multiple hierarchies and complicated interactions among hierarchies and their components. Therefore, system dynamic model can be substituted with more detail entities and relations. Those will be the further research in future.

\section{ACKNOWLEDGMENT}

This work is financially supported by Natural Science Foundation of China (71401171), Chinese PLA General Armament Department Pre-research Fund (9140A19030214JB 11273) and PLA Military Universities 2110 Projects Phase III (4142D4557).

\section{REFERENCES}

[1] J. D. Sterman, Business Dynamics: Systems Thinking and Modeling for a Complex World: McGraw-Hill, 2000.

[2] T. Laverghetta, "Dynamics of Naval Ship Design: A Systems Approach," MIT, 1998.

[3] S. L.Cornford, T. Paulos, L. Meshkat, and M. Feather, "Towards more accurate life cycle risk management through integration of DDP and PRA," presented at the IEEE Aerospace Conference, 2003.

[4] C. Li, Theory and Application of Project Risk Element Transmission Beijing: China Water \& Power Press, 2009.

[5] W. Yuanming, Z. Daozhi, and X. Dahai, "Project Supply Cha in Risk Control Based on the Risk of Transmission," Soft Science, vol. 22, pp. 14, 2008.

[6] L. Da-yong, H. Jian, and L. J.-w. ei, "The Research on Evolvement and Modeling of Risk in Navy Vessel Engineering," Ship Science and Techology, vol. 31, pp. 95-101, 2009.

[7] T. Laverghetta and A. Brown, "Dynamics of Naval Ship Design: A Systems Approach," Naval Engineers Journal, vol. 111, pp. 307-324, 1999.

[8] N. A. Tepper, "Exploring the use of Model-based Systems Engineering (MBSE) to develop systems architectures in naval ship design," MIT, 2010.

[9] N. X.-q. WANG Qi-fan, YOU Jiong, "Advantages of System Dynamics Approach in Managing Project Risk Dynamics," Journal of Fudan University (Natural Science), vol. 44, pp. 201-206, 2005.

TABLE I. Model Variables and ReLation Equations List

\begin{tabular}{|c|c|c|c|}
\hline Type & Name & Property & Relation Equation \\
\hline \multirow{6}{*}{$\begin{array}{l}\text { Risk Level } \\
\text { of Stage }\end{array}$} & Argumentation & Level & $\begin{array}{l}=\text { Argumentation }(\mathrm{t})=\text { Argumentation }(\mathrm{t}-\mathrm{dt})+\mathrm{A} \backslash \text { Risk_Source }-\mathrm{A} \backslash \mathrm{D} \_ \text {Risk_Propagation - } \\
\mathrm{A} \backslash \text { Risk_Mitigation }) * \mathrm{dt}\end{array}$ \\
\hline & Design & Level & $\begin{array}{l}\text { = Design }(\mathrm{t}-\mathrm{dt})+(\mathrm{A} \backslash \mathrm{D} \text { _Risk_Propagation + } \mathrm{D} \backslash \text { Risk_Source - D\C_Risk_Propagation - } \\
\mathrm{D} \backslash \text { Risk_Mitigation }) * \mathrm{dt}\end{array}$ \\
\hline & Construction & Level & 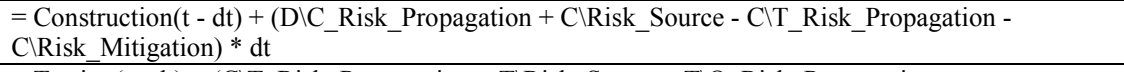 \\
\hline & Testing & Level & $\begin{array}{l}=\text { Testing }(\mathrm{t}-\mathrm{dt})+\left(\mathrm{C} \backslash \mathrm{T} \_ \text {Risk_Propagation }+\mathrm{T} \backslash \text { Risk_Source }-\mathrm{T} \backslash \mathrm{O} \_ \text {Risk_Propagation - }\right. \\
\mathrm{T} \backslash \text { Risk_Mitigation }) * \mathrm{dt}\end{array}$ \\
\hline & Operation & Level & $\begin{array}{l}=\text { Operation }(\mathrm{t}-\mathrm{dt})+\left(\mathrm{T} \backslash \mathrm{O} \_ \text {Risk_Propagation }+\mathrm{O} \backslash \text { Risk_Source - } \backslash \backslash \mathrm{R} \_ \text {Risk_Propagation - }\right. \\
\mathrm{O} \backslash \text { Risk_Mitigation }) * \mathrm{dt}\end{array}$ \\
\hline & Retirement & Level & $=$ Retirement $(\mathrm{t}-\mathrm{dt})+(\mathrm{O} \backslash \mathrm{R}$ _Risk_Propagation $+\mathrm{R} \backslash$ Risk_Source $-\mathrm{R} \backslash$ Risk_Mitigation $) * \mathrm{dt}$ \\
\hline \multirow{6}{*}{$\begin{array}{l}\text { Risk Source } \\
\text { of Stage }\end{array}$} & $\mathrm{A} \backslash$ Risk Source & Rate & $=$ NORMAL $(A \backslash$ Risk Source, 0.1$)$ \\
\hline & $\mathrm{D} \backslash$ Risk Source & Rate & $=$ NORMAL $(\mathrm{D} \backslash$ Risk Source, 0.1$)$ \\
\hline & $\mathrm{C} \backslash$ Risk Source & Rate & $=$ NORMAL $(C \backslash$ Risk Source, 0.1$)$ \\
\hline & $\mathrm{T} \backslash$ Risk Source & Rate & $=$ NORMAL $(T \backslash$ Risk Source, 0.1$)$ \\
\hline & $\mathrm{O} \backslash$ Risk Source & Rate & $=$ NORMAL $(\mathrm{O} \backslash$ Risk Source, 0.1$)$ \\
\hline & $\mathrm{R} \backslash$ Risk Source & Rate & $=$ NORMAL $(\mathrm{R} \backslash$ Risk Source, 0.1$)$ \\
\hline \multirow{6}{*}{$\begin{array}{c}\text { Risk } \\
\text { Mitigation } \\
\text { of Stage }\end{array}$} & A\Risk Mitigation & Rate & 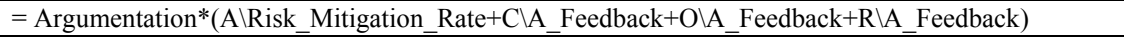 \\
\hline & $\mathrm{D} \backslash$ Risk Mitigation & Rate & $=$ Design* $\left(C \backslash D \_F e e d b a c k+D \backslash\right.$ Risk_Mitigation_Rate+O $\left.\backslash D \_F e e d b a c k+R \backslash D \_F e e d b a c k+T \backslash D \_F e e d b a c k\right)$ \\
\hline & $\mathrm{C} \backslash$ Risk Mitigation & Rate & 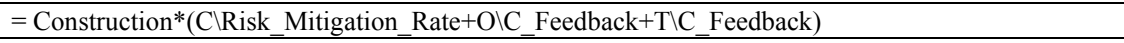 \\
\hline & $T \backslash$ Risk Mitigation & Rate & $=$ Testing*T\Risk_Mitigation_Rate \\
\hline & O\Risk Mitigation & Rate & $=$ Operation*O$\backslash$ Risk_Mitigation_Rate \\
\hline & $R \backslash$ Risk Mitigation & Rate & $=$ Retirement*R $\backslash$ Risk_Mitigation_Rate \\
\hline \multirow{5}{*}{$\begin{array}{c}\text { Risk } \\
\text { Propagation } \\
\text { between } \\
\text { Stages }\end{array}$} & $\mathrm{A} \backslash \mathrm{D}$ Risk Propagation & Rate & $=$ Argumentation-A $\backslash$ Risk_Mitigation \\
\hline & $\mathrm{D} \backslash \mathrm{C}$ Risk Propagation & Rate & = Design-D $\backslash$ Risk_Mitigation \\
\hline & $\mathrm{C} \backslash \mathrm{T}$ Risk Propagation & Rate & $=$ Construction-C\Risk_Mitigation \\
\hline & $T \backslash O$ Risk Propagation & Rate & $=$ Testing-T\Risk_Mitigation \\
\hline & $\mathrm{O} \backslash \mathrm{R}$ Risk Propagation & Rate & $=$ Operation-O $\backslash$ Risk_Mitigation \\
\hline \multirow{5}{*}{$\begin{array}{l}\text { Feedback } \\
\text { for Risk } \\
\text { Mitigation }\end{array}$} & $\mathrm{C} \backslash \mathrm{A}$ Feedback & Auxiliary & $=(\text { Construction } / \text { Argumentation })^{\wedge} 2 / 10$ \\
\hline & $\mathrm{C} \backslash \mathrm{D}$ Feedback & Auxiliary & $=(\text { Construction } / \text { Design })^{\wedge} 2 / 10$ \\
\hline & $T \backslash D$ Feedback & Auxiliary & $=(\text { Testing } / \text { Design })^{\wedge} 2 / 10$ \\
\hline & $\mathrm{O} \backslash \mathrm{D}$ Feedback & Auxiliary & $=(\text { Operation } / \text { Design })^{\wedge} 2 / 10$ \\
\hline & $\mathrm{R} \backslash \mathrm{D}$ Feedback & Auxiliary & $=(\text { Retirement } / \text { Design })^{\wedge} 2 / 10$ \\
\hline
\end{tabular}




\begin{tabular}{|l|l|l|l|}
\hline & O\A Feedback & Auxiliary & $=(\text { Operation/Argumentation })^{\wedge} 2 / 10$ \\
\cline { 2 - 4 } & R\A Feedback & Auxiliary & $=(\text { Retirement/Argumentation })^{\wedge} 2 / 10$ \\
\cline { 2 - 4 } & O\C Feedback & Auxiliary & $=\left(\right.$ Operation/Construction $\wedge^{\wedge} 2 / 10$ \\
\cline { 2 - 4 } & T\C Feedback & Auxiliary & $=(\text { Testing/Construction })^{\wedge} 2 / 10$ \\
\hline
\end{tabular}

